Comunicación y género

ISSNe: 2605-1982

https://dx.doi.org/10.5209/cgen.66507

\title{
Cuestiones de género y ciudadanía en el discurso fílmico
}

\author{
Elia Saneleuterio ${ }^{1}$; Rocío López-García-Torres ${ }^{2}$
}

Resumen. El cine y la ficción seriada, incluida la animación, son transmisores de modelos, de actitudes, de valores y normas de conducta que son replicados, consciente e inconscientemente, por la ciudadanía, al mismo tiempo que la reflejan. Esta doble vertiente de causa y consecuencia de los patrones sociales existentes explica el interés de la comunidad científica por determinar en qué medida mantienen los prejuicios y en qué medida laboran en su superación. Por ello se abordan en este volumen obras fílmicas, en su mayoría protagonizadas por mujeres, con metodologías de análisis que beben del feminismo, que trascienden la mirada masculina y que encaran la problemática de la agencia de los personajes de ficción.

Palabras clave: cine; series de TV; cortos de animación; modelos de género; agencia femenina.

\section{[en] Gender and citizenship issues in film discourse}

\begin{abstract}
Cinema and serial fiction, including animation, are transmitters of models, attitudes, values and norms of behavior which are replicated, consciously and unconsciously, by citizens, and also they reflect it. This double aspect of the cause and consequence of existing social patterns explains the interest of the scientific community in determining the implications of the prejudices they maintain and how they work to overcome them. That is why film works are approached in this volume, mostly starring women, with feminist analysis methodologies, which transcend the male gaze and face the problem of fictional character agency.
\end{abstract}

Keywords: cinema; TV series; animated shorts; gender models; female agency.

Sumario. 1. Introducción y marco teórico. 2. Objetivos. 3. Las miradas masculina, femenina y cuir. 4. La violencia contra la mujer en el cine. 5. Los estereotipos de género en las series de televisión. 6 . Animación infantil y ciudadanía. 7. Conclusiones y prospectiva. 8. Referencias.

Cómo citar: Saneleuterio, E.; López-García-Torres, R. (2019). Cuestiones de género y ciudadanía en el discurso fílmico. Revista Comunicación y género, 2 (2) 2019, 147-159.

\section{Introducción y marco teórico}

Resulta imposible medir la verdadera magnitud del impacto de los medios de comunicación en los cambios sociales y políticos en lo que a la variable "género" se refiere. Los medios de comunicación constituyen instrumentos de socialización permanente y de construcción de referentes, son transmisores de modelos, de actitudes, de valores y normas de conducta que son replicados, consciente e inconscientemente, por la ciudadanía. Y ello ocurre con una intensidad especial en el discurso fílmico:

\footnotetext{
Universitat de València

2 Universidad CEU Cardenal Herrera
} 
es indudable que las imágenes y las representaciones de género que aparecen en las producciones audiovisuales son causa y consecuencia, simultáneamente, de los patrones sociales existentes.

En esta doble vertiente radica la necesidad de analizar no solo si estos medios -cuya influencia en la opinión pública es innegable- acompañan, promueven o dificultan los cambios sociales, como acota Betty Friedan (2016), sino que la situación de partida es mucho más compleja $\mathrm{y}$, con frecuencia, tendente hacia ambos extremos. Por ello, se trata de determinar en qué medida mantienen los prejuicios y en qué medida laboran en su superación.

Si nos centramos en los modelos de género, estos funcionan como un patrón que amolda la percepción, los pensamientos y los actos de todos los miembros de la sociedad (Bourdieu, 1998). Esto sucede porque se asimilan de manera inconsciente y, por ello, es fácil no "percibirlos" o percibirlos como carentes de defectos, dado que se han naturalizado. Uno de los objetivos de los estudios de género es precisamente mostrar sus incoherencias e imperfecciones de los estereotipos aprendidos y transmitidos durante generaciones (Butler, 1990). El debatido concepto de género ha encontrado en algunos ambientes un carácter de herramienta de análisis social e instrumento político. En este sentido, van en aumento los estudios e investigaciones de los contenidos culturales que se transmiten desde los distintos medios de comunicación, y no son pocos quienes se preocupan concretamente por la representación mediática de hombres y mujeres (López García-Torres y Saneleuterio, e/p).

Con este planteamiento nace "Cuestiones de género y ciudadanía en el discurso fílmico", de la confluencia de dos marcos teóricos: por un lado, los estudios que abordan el impacto social de los distintos contenidos culturales desde perspectivas de género (Benlloch, 2008); por otro, el creciente interés por la repercusión de los modelos de ficción en el desarrollo de las personas, en especial en lo relativo a la educación en cuestiones de igualdad entre mujeres y hombres (Pascual y Cabo, 2010).

Este trabajo colectivo tiene un carácter interdisciplinar para visibilizar las implicaciones de algunas obras fílmicas de ficción, sus contenidos, enfoques y propuestas. Partiendo de este campo, se trata concretamente de estudios de género vinculados tanto a largometrajes como a series televisivas y cortos de animación: aportaciones feministas, estudios de personajes de ficción desde una perspectiva de género, visibilización de personas marginadas por su sexualidad... Todo ello mediante una metodología analítico-interpretativa, de carácter sociocrítico.

Además, se consideran algunas de las obras analizadas en su calidad de secuela, adaptación o apropiación. Sanders (2015) sostiene que este tipo de productos culturales, sean precuelas, secuelas, extensiones o amplificaciones, interesan por su capacidad de subrayar o contradecir aspectos determinados o ausencias desconcertantes del original. Por ello, el análisis comparativo permite a la comunidad científica desgranar cómo las relaciones intertextuales profundizan en unos aspectos y no en otros; por ejemplo, dando voz a la conciencia social o política de personajes hasta ahora silenciados o no potenciados.

Dentro de este complejo marco teórico, también destaca como categoría de análisis la llamada -sobre todo en el ámbito norteamericano- "agencia femenina". Con el término "agencia”, Judith Butler (1988) se refería a la capacidad de elección del sujeto y a sus estrategias de resistencia en contextos adversos. Primeramente, este constructo teórico se aplicó a la categoría "mujer", por la magnitud de su repre- 
sentación en el mundo y el contraste con su histórica invisibilización, pero desde hace años se aplica también a otros colectivos minoritarios históricamente pasivos o pasivizados, cuyas reivindicaciones explican que los análisis feministas se hayan integrado en una perspectiva más amplia, denominada "de género".

Por último, desde esta introducción queremos subrayar la paradoja de una realidad que cabría abordar desde un punto de vista nuevo: los propios estudios de género parecen haber seguido una evolución en que lo femenino no solo es cuestionado, sino también invisibilizado. Esta idea puede quedar sintetizada con la frase "la mujer molesta", enunciado con el que Rosa María Rodríguez Magda (2019) trae esta cuestión al centro del debate, y cuya paradoja este monográfico, en cierta medida, también representa.

\section{Objetivos}

El planteamiento de este número monográfico giró, desde el principio, en torno al estudio del discurso fílmico desde una perspectiva que incluyera el género como problematización cultural o como punto clave en las relaciones sociales y en la construcción de la ciudadanía. A priori, la convocatoria daba cabida a estudios sobre películas u obras de animación para público infantil o adulto, dirigidas, guionizadas o protagonizadas tanto por mujeres como por personas marginadas por su sexualidad. Asimismo, se admitieron propuestas sobre la problematización cinematográfica de cuestiones de género o sobre personajes de ficción estudiados desde esta perspectiva.

Así, el abanico temático que extendimos en la convocatoria pretendía hallar eco en investigadores e investigadoras de todo el mundo que se interesaran por atender uno o varios de estos puntos:

1. Obras fílmicas para público infantil o adulto, dirigidas, guionizadas o protagonizadas por mujeres o por personas marginadas por su sexualidad.

2. Aproximaciones cinematográficas que aborden la ciudadanía desde la perspectiva de la diversidad sexual.

3. Estudios de género sobre el discurso fílmico, femenino o no, o sobre adaptaciones fílmicas de obras literarias escritas por mujeres.

4. La educación para la ciudadanía a través del cine desde perspectivas de género: autoras o protagonistas.

5. La agencia femenina o marginal en los personajes de ficción.

6. Investigaciones comparativas que midan la presencia de autoras, artistas o personajes femeninos en el cine.

Aunque, por razones evidentes, no se han podido abordar con profundidad todas las posibilidades de investigación citadas, el conjunto de artículos seleccionados en el monográfico sí responde a estos objetivos en mayor o menor medida, como a continuación mostraremos.

\section{Las miradas masculina, femenina y cuir}

Michela Russo aborda la dialéctica entre mirada masculina y mirada femenina en el cine a través de "Devolver la mirada: el personaje de Vera en La piel que ha- 
bito de Pedro Almodóvar". Russo consiguió su doctorado en Filosofía Teórica y Política en el Instituto Italiano de Ciencias Humanas (SUM) de Nápoles, en Italia. Es candidata para defender su segunda tesis doctoral en Estudios Latinoamericanos en la Universidad de Texas A\&M (College Station, Texas, EE. UU.). Sus intereses académicos abarcan los estudios latinoamericanos, los estudios queer y de género, estudios fílmicos y artes visuales, la filosofía política y la estética continental. Sus áreas de investigación actuales son la historia política de América Latina entre los siglos Xx y Xx, con particular atención a los procesos de construcción nacional y sus implicaciones raciales y de género, así como los estudios de cine latinoamericano contemporáneo. Actualmente, Michela Russo es profesora en la Universidad de Michigan, Ann Arbor (Estados Unidos), donde imparte cursos en español sobre Género y Sexualidad en el Mundo Hispano, Culturas de Frontera, Introducción a los Estudios Culturales Latinoamericanos, Conversación en Español con Cine...

Su ensayo analiza el movimiento de la cámara, sus ángulos y tomas, los cuales materialmente establecen la mirada que estructura una película y construye a sus personajes. Russo considera la noción de "mirada masculina" desarrollada por Mulvey (2009) como una mirada que corresponde al placer masculino objetivador. Suplementa esta noción con la definición de "mirada femenina" propuesta por Soloway (2016), y aplica el contraste de ambas a un personaje transexual suigéneris, el/la protagonista de La piel que habito, Vera. A través de este personaje, Almodóvar (2011) exacerba la dialéctica entre las miradas masculina y femenina hasta romperla, a la vez tematizando una noción de feminidad más amplia capaz de instituir una "mirada cuir", adaptación gráfica correspondiente a la fonética del término anglosajón queer. Así, Russo abraza el término propuesto según las reglas de la Real Academia Española para la incorporación de extranjerismos en nuestra lengua y da un paso al frente en la apropiación del debate para el ámbito iberoamericano.

La dialéctica entre miradas la que encontramos también en el análisis comparativo de Cristina Martínez Istillarte "María Egipciaca y Breaking the Waves: la irresistible atracción de la prostituta mártir". Esta doctoranda en el Departamento de Español y Portugués de la Tulane University (EE. UU.), que previamente estudió en la Universitat de València, la Universidad de Sheffield y en Florida Atlantic University, está especializándose en estudios de alteridad con énfasis en la representación de inmigrantes y sujetos en la diáspora. Entre sus intereses de investigación también figuran la xenofobia y el racismo hacia minorías en la cultura contemporánea española.

Como explica la autora, la vida de María Egipciaca ha sido por siglos imaginada y diseminada a mano de varones, en su mayoría miembros del clero. Dentro de este corpus literario se evidencia toda una manera de escribir sobre conversiones de mujeres, espacio donde se idealiza el sacrificio corporal femenino y, por ende, se promueven imágenes e ideas esencialistas sobre la mujer y sobre lo femenino. Su estudio analiza la intertextualidad implícita, pero demostrada ampliamente a través de una investigación cualitativa, entre la leyenda de María Egipciaca y el filme Breaking the Waves (1996), del director danés Lars Von Trier.

Brígida M. Pastor, por su parte, nos propone "Pride and Prejudice: Fashioning a Cuban Discourse of "Difference" in Fresa y Chocolate" ["Orgullo y prejuicio: modelando el discurso cubano de la diferencia en Fresa y Chocolate"]. La autora es investigadora honorífica de la Universidad de Swansea-Gales, en el Reino Unido. Es doctora en Estudios Hispánicos por la Universidad de Bristol (Reino Unido), así como por la Universidad Complutense de Madrid y la Universidad de 
Sao Paulo-USP. En 1999 recibió un reconocimiento honorífico de la Cátedra de Estudios de Género del Instituto de Literatura y Lingüística-La Habana. Entre los puestos previos que ha ocupado destaca el de profesora titular en la Universidad de Glasgow o investigadora del CSIC. Ha organizado varios congresos y simposios internacionales y ha sido profesora invitada en foros científicos en los Estados Unidos, Australia, Reino Unido, Brasil, Argentina, Cuba y España. Es miembro de varios comités editoriales de importantes revistas científicas de impacto internacional y su último proyecto sobre ficción infantil y juvenil en 2016 recibió el reconocimiento de las Naciones Unidas por su innovadora contribución a los estudios de género. Son varias las líneas que ha emprendido durante su carrera investigadora: literatura española e hispanoamericana de los siglos XIX y XX, con particular interés en la literatura infantil y los temas de género, la literatura femenina y feminista, el cine español y latinoamericano, centrando sus investigaciones especialmente en el ámbito cubano.

Tal y como explica la autora, el cine ha surgido como un espacio de producción en el que la representación de las sexualidades se construye e inscribe dentro del discurso simbólico del poder, y la película cubana Fresa y Chocolate (1993), basada en la novela de Senel Paz El lobo, el bosque y el hombre nuevo (1990), representa un ejemplo esclarecedor. El objetivo de los directores, Tomás Gutiérrez Alea y Juan Carlos Tabío, es hacer explícita la construcción social del orden simbólico dominante y los problemas involucrados en su deconstrucción, para mostrar hasta qué punto las políticas sexuales están profundamente arraigadas en todas las formaciones culturales y sociales a lo largo de la historia. Pues bien, este estudio intenta dilucidar la relación dialéctica entre el orden simbólico social -la norma- y la conciencia individual. Los cineastas construyen estratégicamente la relación, los conflictos y las contradicciones que surgen de ella, incluida la crítica de algunos aspectos de la Revolución Cubana, a saber, el pathos de la cultura cuir, que potencia la diferencia sexual como un elemento de cambio social.

\section{La violencia contra la mujer en el cine}

Elizabeth Montes Garcés, desde su experiencia investigadora en el tema (Rocha y Montes Garcés, 2010), aporta un ensayo sobre "Violencia y sometimiento en La Sirga de William Vega". Esta profesora titular de la Universidad de Calgary, en Canadá, obtuvo su doctorado en la University of Kansas (EE. UU.) en 1993 y en efecto se especializó en estudios de género asociados con la literatura, el cine y los cómics en Latinoamérica, con títulos como El cuestionamiento de los mecanismos de representación en la novelística de Fanny Buitrago (1997) o Relocating Identities in Latin American Cultures (2007). Sus estudios sobre escritoras latinoamericanas se hallan recogidos en revistas académicas prestigiosas como Texto Crítico, Letras Femeninas, Revista de Literatura Mexicana Contemporánea o Revista Canadiense de Estudios Hispánicos. Su ensayo incluido en este monográfico analiza La Sirga (2012), de William Vega, una película que recrea la vida de una niña que huye de su pueblo cuando los paramilitares matan a sus padres. Utilizando los conceptos de Slavoj Žižek (2009) sobre la violencia sistémica y de Judith Butler (1988; 1997) sobre la sujeción y el poder, la autora demuestra que en la película la mirada masculina actúa como un mecanismo de vigilancia que intenta construir a la protagonista como un 
sujeto obediente que no se debe desviar del papel tradicional asignado a las mujeres colombianas.

M. a del Mar López-Cabrales analiza “Alma gitana y Carmen y Lola: dos miradas transversales a la violencia contra la mujer en la etnia gitana”. La autora es catedrática de Lengua y Literatura en el Departamento de Lenguas, Literaturas y Culturas de la Colorado State University (EE. UU.) y editora de la revista Confluencia. Fue profesora invitada en la Universidad de Cádiz (1999) y en el marco del programa Semester at Sea (2000, 2001, 2017). En la actualidad investiga asuntos de género y estudios culturales en Cuba, Latinoamérica y España (López-Cabrales, 2000; 2007; 2008; 2013). Precisamente, en este ensayo analiza cómo en las dos películas mencionadas en el título -Alma gitana (1996), de Chus Gutiérrez, y Carmen y Lola (2018), de Arantxa Echevarría- se cuestiona la violencia contra la mujer en la comunidad gitana y se propone la necesidad de que las generaciones más jóvenes vayan cambiando y construyendo sus vidas desde la igualdad, sin por ello tener que desestimar totalmente la cultura ni las tradiciones de sus ancestros. Cabe destacar la autoría femenina de los filmes, así como el dato de que tanto Gutiérrez como Echevarría son mujeres que, sin pertenecer a la etnia gitana y partiendo de un conocimiento profundo y con gran respeto, intentan articular en sus textos fílmicos posibles respuestas constructivas para enfrentar el tema de la violencia machista en la comunidad gitana.

\section{Los estereotipos de género en las series de televisión}

Si la cuestión es dilucidar si los medios acompañan, promueven o dificultan los cambios sociales en lo que a igualdad entre hombres y mujeres se refiere, no podemos negar el papel que la ficción seriada tiene en una época como la que vivimos (Gregori-Signes, 2017; Menéndez y Zurián, 2014), en la que parece que hemos alcanzado la edad de oro en las series televisivas (Cascajosa, 2016). Ello se debe al acierto de su formato en las plataformas de televisión a la carta, su éxito de audiencia y su reconocimiento por parte de la crítica, que le reconoce el estatus de la literatura o el arte (Muñoz, 2016).

En este contexto, Paula Parra García, Inmaculada Postigo Gómez y Teresa Vera Balanza, pertenecientes al área de Periodismo y Comunicación, nos presentan uno de los frutos de sus investigaciones sobre la representación de las mujeres, titulado "Resistencias y variaciones de la construcción del género en la nueva ficción seriada. Girls y Big Little Lies". La primera de las autoras es graduada en Periodismo, con un máster en Dirección Estratégica e Innovación en Comunicación por la Universidad de Málaga. Su línea de investigación se centra en los estudios de género, en concreto, en el papel de las mujeres en los productos audiovisuales contemporáneos como son las series de televisión y los transmitidos por otras plataformas. Entre sus proyectos cercanos se encuentra comenzar su formación como doctora en Comunicación Social y la publicación de varios artículos que tienen como eje temático las representaciones de género en el audiovisual. Postigo Gómez, por su parte, es profesora titular de la Facultad de Ciencias de la Comunicación de la Universidad de Málaga. Sus líneas de investigación alcanzan el análisis de las producciones discursivas desde una perspectiva crítica. Ha dirigido el Observatorio del Tratamiento Informativo de la Violencia de Género con especial atención a la identidad étnica y cultural, proyecto de investigación de excelencia de la Junta de Andalucía. En la actualidad 
codirige como IP el proyecto de investigación "Produsage juvenil en las redes sociales y manifestaciones de las desigualdades de género: nuevas formas de violencia" (referencia: FEM2017-83302-C3-2-P), dentro del Programa Estatal de Investigación Científico y Técnica de Excelencia (MINECO). Teresa Vera, codirectora del mencionado proyecto, es profesora titular de Periodismo, integrante del Seminario de Estudios Interdisciplinarios de la Mujer (SEIM-UMA) y de la Comisión Permanente de Igualdad de la misma universidad. Sus líneas de investigación se centran el análisis de representaciones y discursos del género y en la indagación sobre las teorías comunicativas desde la perspectiva crítica.

Como bien introducen estas tres investigadoras de la Universidad de Málaga, vivimos en una sociedad en la que conviven y persisten las diferencias entre lo que cultural y socialmente se adscribe al género. Esta distinción se basa en una estructura de estereotipos relacionados con el género que afecta a todos los ámbitos de nuestra vida cotidiana, incluidos los medios audiovisuales como dispositivos o tecnologías del género. Construidos como discursos de lo cotidiano, ni siquiera cuestionamos lo que vemos en pantalla y lo asumimos como representaciones de la realidad. En este sentido, las autoras proponen un análisis de las series Girls (2012-2017) y Big Little Lies (2017-2019), mostrando y explicando qué roles de género entran en juego en estas ficciones seriadas cuyo protagonismo recae fundamentalmente en mujeres.

\section{Animación infantil y ciudadanía}

En la construcción de la ciudadanía, también destaca un tipo muy concreto de productos culturales relacionados con el cine en su sentido más clásico: las producciones de animación. Y precisamente tienen un papel destacado por la inclinación natural propia de la infancia hacia sus formas y propuestas visuales o musicales, hacia la fantasía de la ficción, la atracción del color o la textura, elementos que, en realidad, agradan a espectadores de todas las edades. Sin embargo, el público infantil presenta una característica frecuente que es puesta de manifiesto por Paredes (2010): el alcance de las propuestas cinematográficas trasciende los límites temporales del visionado del filme o material televisivo; para la mayoría de niños y niñas, las fantasías que estas obras les inspiran impregnan sus juegos, sus conversaciones y su vida cotidiana, en general. Se trata de:

servirse del cine para abordar de una forma viva la educación en valores; $y$, sobre todo, de aprovechar el cine, por su conexión con la emoción, con el sentimiento, con la belleza, con el arte, para no olvidar que la educación ha de ser integral, que la meta de la educación es la persona total. (Pereira, 2005: 20)

En efecto, el cine, representación de historias y subjetividades mediante el discurso y lenguaje audiovisual, desempeña, entre sus funciones, una muy ligada a la que cumple la literatura en la construcción y la preservación de las identidades, entendidas como representaciones y categorizaciones del mundo y de nosotros mismos. No en vano el cine para niños entra dentro de los ámbitos de estudio de la literatura infantil y juvenil (Cano Calderón, 1993; Mínguez-López, 2015), de de ahí la importancia de su análisis como representación alternativa de la realidad y constructora de 
futura ciudadanía (Saneleuterio y López-García-Torres, 2018; 2019; Saneleuterio, 2019).

Oltra y Pardo (2015), por su parte, argumentan a favor de la utilización de las distintas formas y géneros literarios como modo de expresar y construir diferentes identidades nacionales, culturales, religiosas, lingüísticas o sexuales, e incluso imponerlas o destruirlas, según sugieren. Pero las identidades se construyen, se expresan y se transmiten no solo a partir de las lenguas y de las literaturas, como ellos afirman, sino también a través de otros productos culturales, pues no podemos perder de vista que, hoy en día, la ficción está mucho más presente a través del cine y de las series televisivas que de la propia literatura. La realidad es que las generaciones actuales se nutren con más frecuencia del material audiovisual que de los libros en sí; de ahí la relevancia de prestarle atención -como objeto de estudio específico incluido en este monográfico-al discurso fílmico más consumido por el público infantil: los dibujos animados.

Rebeca Cristina López González pone algunas de estas cuestiones de manifiesto en "Cortos de animación en la red para todos los públicos y género: temáticas y roles de siempre contados como nunca". Licenciada en Traducción e Interpretación por la Universidad de Vigo, obtuvo en la misma universidad el título de doctora tras defender su tesis sobre el humor intertextual hallado en un corpus de cine de animación dirigido a todos los públicos. Forma parte del grupo de investigación GALMA Observatory for Media Accessibility. Sus líneas de investigación se centran en la traducción especializada: la traducción audiovisual, la traducción económica, la jurídica y la literaria. Como especialista en literatura infantil y animación (López-González, 2018a; 2018b), en este trabajo se centra en el discurso narrado por cuatro cortos de animación muy recientes: Purl (2019) y Kitbul (2019), realizados por Pixar, One Small Step (2018), creado por la joven productora de origen asiático Taiko Studios, y Hé Mademoiselle (2015), procedente de la Escuela Superior de Artes y Oficios ESMA, en Francia. Pese a su origen tan diverso, todos estos trabajos comparten una serie de rasgos comunes, que orientan su temática hacia la deconstrucción de estereotipos y la igualdad entre hombres y mujeres. El núcleo de cada historia enfoca el atemporal mundo femenino con propuestas interesantes para su análisis desde el punto de vista de género, de modo que el objetivo de este trabajo es profundizar en el enfoque narrado y averiguar hasta qué punto cada historia puede romper con los estereotipos de género y brindar una lección a las nuevas generaciones, tan orientadas a YouTube, plataforma desde donde se suelen difundir este tipo de trabajos audiovisuales.

\section{Conclusiones y prospectiva}

Para ser honestas, hemos de reconocer que no todas las líneas de investigación sobre el discurso fílmico que abrió la convocatoria han sido transitadas finalmente en el monográfico "Cuestiones de género y ciudadanía en el discurso fílmico". Por ejemplo, nos habría gustado haber podido recoger también estudios comparativos e investigaciones que midieran la presencia de autoras, artistas o personajes determinados en entornos fílmicos acotados, como puedan ser una época o territorio concretos, los listados de obras galardonadas o nominadas a distintos premios, e incluso el canon de cine fórum educativo. Quede todo ello como prospectiva y como anzuelo para los investigadores e investigadoras que se acerquen a estas páginas. 
Por ello y a pesar de ello, queremos concluir con un avance de lo que supone el esfuerzo colectivo de abordar el discurso fílmico desde el punto de vista de la construcción de una ciudadanía igualitaria, así como con el reconocimiento de que queda mucho por hacer: en este sentido, es sintomático que conozcamos a los hermanos Lumière y no, por ejemplo, a Alicie Guy, si bien desde hace unos años su figura se empieza a reivindicar como la verdadera impulsora y pionera del cine de ficción, iniciándose en ello solo unos meses después de la invención del cinematógrafo (De Lucas Ramón, 2011; De Souza Machado, 2018; El Periódico, 2017; Kilston, 2010; Landeira, 2017; McMahan, 2006). ¿Es normal que la cultura generalizada ignore a quien rodara más de mil películas en una época tan temprana? ¿Por qué la aportación de tantos y tantos hombres se conoce sin más y las de las mujeres necesitan que alguien se preocupe por reivindicarlas como si sus méritos intrínsecos no fueran suficientes? Parece que nos cuesta escapar del paternalismo secular o que en la naturaleza de las personas es más natural decantarse por lo masculino. Por otro lado, cualquier revisión a la literatura sobre estas cuestiones evidencia que son fundamentalmente mujeres quienes se preocupan por ellas. Sin ir más lejos, la autoría de este monográfico es enteramente femenina, y el objeto de sus estudios, películas mayoritariamente dirigidas o producidas por varones.

Así, este número monográfico abre nuevas preguntas, pero también traza conclusiones firmes sobre las que transitar en busca de respuestas. Si en La piel que habito Almodóvar aborda el tema trans como una manera de permanecer en la transición o en la fluidez entre un género y otro, Russo concluye que las miradas masculina y femenina, analizadas pormenorizadamente en su investigación, dan lugar en la producción de este filme a la emanación de una nueva mirada, la "cuir". Para Russo no se trata solo de una técnica representativa narrativa, cinematográfica y visual, sino que estamos ante la articulación de una epistemología que, según ella, atenta a las fisuras y a los puntos ciegos de los discursos dominantes y que, al mismo tiempo, permite repensar lo femenino y lo masculino trascendiendo categorías fijas y normativizantes de lo sexual, como un desafío técnico e ideológico a la dialéctica entre mirada masculina y mirada femenina en el cine, tal y como Russo demuestra con el análisis de los planos $\mathrm{y}$ de los puntos de vista de la cámara.

Respecto a Breaking the Waves (1996), del director danés Lars Von Trier, el análisis de Martínez Istillarte demuestra hasta qué punto esta película cuestiona la idealización del sacrificio corporal femenino y la promoción de imágenes e ideas esencialistas sobre la mujer y sobre lo femenino a través fundamentalmente del intertextexto sobre el que opera implícitamente: las hagiografías de María Egipciaca. De esta manera, la autora concluye que la naturaleza subversiva tanto de la santa como de la protagonista del filme conforma una especie de catálisis que inspira o inicia la ruptura con las respectivas comunidades. En la vida de ambas, ello desencadena una especie de exilio en forma de peregrinaje y sacrificio que acaba con la muerte, salvación y elevación de sus figuras, obviamente a diferente escala. Aunque en cada argumento la actividad sexual de estas mujeres cumple objetivos distintos, en ambos sirve para subrayar la agencia femenina. En el caso de la apropiación de Trier, su narrativa incluye e informa de preocupaciones ideológicas y culturales apropiándose del perfil de la prostituta mártir con el fin de usar este modelo de mujer como crítica cultural y sus efectos destructivos, aspectos y contradicciones aparentemente silenciados dentro del corpus literario encabezado por María Egipciaca y María Magdalena. 
Si continuamos con el juego de miradas que explica la singularidad de los diferentes filmes analizados en este monogáfico, encontramos que Brígida M. Pastor, por su parte, concluye que los directores de Fresa y chocolate subrayan, ya desde el título, la oposición diametral de los protagonistas mediante la yuxtaposición de dos sabores antagónicos, así como la idea de que la combinación -léase "las elecciones de la vida"- es cuestión de gustos. En general, la película se muestra como un ejemplo elocuente de la retórica de la "diferencia", concepto con que la autora alude a un reflejo de la realidad de la "otredad / diferencia", que constituye un reto aún no superado ni en Cuba, donde se contextualiza la película, ni en la cultura global en general.

Pasamos a enfocar ahora las conclusiones que Montes Garcés y López-Cabrales extraen de los análisis de los discursos fílmicos sobre la violencia ejercida contra las mujeres. En La Sirga, de William Vega, son la ocularización y la focalización los mecanismos mediante los que el director logra contagiar el miedo y la zozobra que embargan a miles de niñas y mujeres, en este caso en el contexto colombiano. Montes Garcés desentraña los movimientos de cámara y la construcción del discurso para mostrar el tremendo impacto tanto de la violencia visible como de la que se esconde soterrada en esa sociedad: por un lado, la violencia subjetiva de los grupos paramilitares sobre la población civil y, por otro, la violencia objetiva que se ejerce sobre el sujeto femenino en forma de amenazas o abusos sexuales. Se trata, esta última, de una violencia sistémica contra la que cabe luchar reinventándose como sujeto, como hace la protagonista del filme al buscar la sororidad y trabajar por su independencia y autonomía.

Por su parte, Alma gitana (1996), de Chus Gutiérrez, y Carmen y Lola (2018), de Arantxa Echevarría, muestran el poder central de la televisión y de las redes sociales, respectivamente, y su papel conflictivo en la imbricación de las costumbres gitanas en para la realización y libertad de las mujeres. El análisis comparativo de estas dos películas realizadas con más de veinte años de diferencia evidencia que, a pesar de ello, no han evolucionado mucho las ideas preconcebidas en el imaginario gitano en cuanto a lo que debe ser un hombre y lo que debe ser una mujer. En concreto, destacan en este contraste el tema del matrimonio, el poder patriarcal y la violencia machista, en ambos casos cuestiones impuestas y envueltas en similar inmovilismo frente a la presión exterior. Por ello, la contribución de López-Cabrales es una mirada transversal (ginocine) que apuesta por un enfoque feminista interseccional, típico de la tercera ola del Feminismo, en el que se atiende a factores no solo de género, sino también de raza, etnia, nivel socioeconómico, orientación sexual, etc. En definitiva, las dos películas subrayan el esfuerzo y los obstáculos de las generaciones más jóvenes a la hora de cambiar la mentalidad patriarcal gitana. Los finales abiertos de ambas cintas parecen darnos a entender que no hay lugar para sus protagonistas por sentirse distintas en su entorno familiar tradicional y la lectura de López-Cabrales incide en que es necesario seguir planteando estas cuestiones a través del cine o de otros productos culturales para seguir abriendo las mentes y aportar elementos para la construcción de una futura ciudadanía más justa e igualitaria.

Algunos de esos elementos son los que toma en consideración la investigación de Parra García, Postigo Gómez y Vera Balanza para el caso de la ficción seriada. Su análisis del discurso narrativo de dos de las series más ampliamente aplaudidas por la crítica feminista muestra tanto fortalezas como debilidades en cada una de ellas. Los resultados llevan a las autoras a concluir que en la serie Big Little Lies, y en 
mucha menor medida en Girls, persisten matices tradicionales en la construcción del género, si bien en este punto es donde comparativamente más distancia encuentran entre las dos propuestas seriadas: mientras que las protagonistas de Big Little Lies abrazan ciertos prototipos de mujer perfecta impuestos por Hollywood, no desprovistos, hasta el final de la primera temporada, de la tradicional rivalidad femenina, en Girls se nos muestra una imagen mucho más compleja y aproximada a la realidad de las mujeres, mostrándolas con naturalidad en las actividades cotidianas más básicas y menos elegantes.

Finalmente, respecto del análisis de la animación infantil, en la contribución de López González se concluye que, a pesar de su formato "cándido inocente y de puro entretenimiento", los cortos animados tienen un potencial reivindicativo y didáctico que la brevedad del mensaje ayuda a difundir. En este caso, las cuatro obras analizadas muestran personajes que superan diversas situaciones dramáticas cuestionando al mismo tiempo los roles de género -incluso cuando se trata de protagonistas no humanos-y poniendo en valor características tradicionalmente menospreciadas por ser asociadas con lo femenino. Asimismo, se percibe en ellos la aportación de las mujeres al proceso creativo de la animación infantil, y se concluye que se trata de cortos que ayudan a remover conciencias tanto para su uso en contextos educativos como para espectadores adultos.

Este monográfico que presentamos es, en definitiva, fruto del trabajo colectivo de las coordinadoras, de las autoras y de los más de veinte revisores que han evaluado a ciegas todas las investigaciones recibidas y que, con su criterio y experiencia, nos han permitido realizar la mejor selección posible de entre todas las colaboraciones propuestas. Las observaciones y sugerencias de mejora realizadas por este equipo de doctores y doctoras han contribuido indudablemente a la calidad científica de aquellos trabajos que finalmente han sido publicados en este número, consiguiendo un rigor y una claridad expositiva probados al crisol de hasta cuatro revisiones del texto.

Además, es preciso agradecer su confianza a la revista Comunicación y Género, concretamente a Yanna G. Franco y a Marian Blanco Ruiz, directora y secretaria, respectivamente. Confiamos en que los artículos incluidos en este número contribuyan al propósito del equipo editorial de la revista de hacer de Comunicación y Género una publicación de referencia.

\section{Referencias}

Alma gitana (1996) Chus Gutiérrez [filme]. España, Samarkanda.

Benlloch, I. (coord.) (2008) Imaginario Cultural, construcción de identidades de género y violencia: formación para la igualdad en la adolescencia. Madrid, Instituto de la Mujer. Disponible en: http://www.inmujer.gob.es/areasTematicas/estudios/serieEstudios/docs/ imaginarioCultural.pdf

Big Little Lies (2017-2019) David E. Kelley [serie TV]. EE. UU., Pacific Standard, Blossom Films, David E. Kelley Productions.

Bourdieu, P. (1998) La domination masculine. París, Seuil.

Breaking the Waves (1996) Lars Von Trier [filme]. Dinamarca, Zentropa.

Butler, J. (1988) "Performative Acts and Gender Constitution: An Essay in Phenomenology and Feminist Theory" en Theater Journal, 40, (4), pp. 519-531. Disponible en: https:// www.amherst.edu/system/files/media/1650/butler_performative_acts.pdf 
Butler, J. (1990) Gender Trouble. Feminism and the Subversion of Identity. Nueva York, Routledge.

Butler, J. (1997) The Psychic Life of Power: Theories in Subjection. Stanford, Stanford University Press.

Cano Calderón, A. (1993) “El cine para niños, un capítulo de la literatura infantil” en Revista Interuniversitaria de Formación del Profesorado, 18, pp. 53-57.

Carmen y Lola (2018) Arantxa Echevarría [filme]. España, Tvtec Servicios Audiovisuales / ICAA.

Cascajosa, C. (2016) La cultura de las series. Barcelona, Laertes.

De Lucas Ramón, I. (2011) La pionera oculta: Alice Guy en el origen del cine [Tesis doctoral dirigida por Juan Miguel Company Ramon y Antonio Méndez Rubio]. Valencia, Universitat de València.

De Souza Machado, S. (2018) "Uma Outra História: a "esquecida" nação do Cinema das Mulheres" en História Revista, 23, (1), pp. 4-27.

El Periódico (2017) “Alice Guy, la olvidada madre del cine” en El Periódico, 23 de marzo. Disponible en: https://www.elperiodico.com/es/ocio-y-cultura/20170323/alice-guyprimera-directora-historia-cine-5919755

Fresa y Chocolate (1993) Tomás Gutiérrez Alea y Juan Carlos Tabío [filme]. Cuba-EspañaMéxico.

Friedan, B. (2016) La mística de la feminidad. Madrid, Cátedra.

Girls (2012-2017) Lena Dunham [serie TV]. EE. UU., Apatow Productions.

Gregori-Signes, C. (2017) “Apparently, women don't know how to operate doors: A corpus-based analysis of women stereotypes in the TV series $3^{\text {rd }}$ rock from the sun", en International Journal of English Studies, 17, (2), pp. 21-43. Disponible en: http://revistas. um.es/ijes/article/view/257311/220541

Hé Mademoiselle (2015) Claire Bataille, Victor Dulon, Pierre Herzig, Gaël Lang y Léa Parker [corto de animación] Francia, Ecole Supérieure des Métiers Artistiques (ESMA).

Kilston, L. (2010) “Alice Guy Blaché” en Art in America, 98, (5), pp. 155-156.

Kitbull (2019) Rosana Sullivan [corto de animación]. EE. UU, Pixar.

La piel que habito (2011) Pedro Almodóvar [filme]. España, El Deseo.

La Sirga (2012) William Vega [filme]. Colombia, Cineplex.

Landeira, L. (2017) “El extraño caso de... Alice Guy” en Cinemanía, 263, pp. 18-18.

López González, R. C. (2018a) "Los conflictos en la literatura infantil y juvenil: una lección para el lector", en LiLetrad, 4, pp. 213-224.

López González, R. C. (2018b) "The Art of Including Art in Animation: DreamWorks' Intertextual Games for All", en Journal of Literary Education, 1, pp. 107-129.

López-Cabrales, M. M. (2000) La pluma y la represión: Escritoras contemporáneas argentinas. Nueva York, Peter Lang.

López-Cabrales, M. M. (2007) Una isla con cara de mujer. Prominentes mujeres de la cultura en Cuba. Nueva Jersey, Ediciones Nuevo Espacio.

López-Cabrales, M. M. (2008) Rompiendo las olas durante el periodo especial. Creación literaria y artística de mujeres en Cuba. Buenos Aires, Corregidor.

López-Cabrales, M. M. (2013) Marinera en tierra adentro. Edición anotada de la obra narrativa de Pilar Paz Pasamar. Málaga, Presea.

López-García-Torres, R., y E. Saneleuterio (e/p) "In/dependencia de hombres y mujeres en cuatro producciones de Disney y su impacto social" en Comunitania. Revista Internacional de Trabajo Social y Ciencias Sociales.

McMahan, A. (2006) Alice Guy Blaché. Madrid, Plot. 
Menéndez, M. I., y F. Zurián (2014) "Mujeres y hombres en la ficción televisiva norteamericana hoy" en Anagramas: Rumbos y Sentidos de la Comunicación, 13, (25), pp. 54-61. Disponible en: https://dialnet.unirioja.es/servlet/articulo?codigo $=5053612$

Mínguez-López, X. (2015) “Una definición altamente problemática. Los problemas de definición de la LIJ" en Lenguaje y textos, 41, pp. 5-105.

Montes Garcés, E. (1997) El cuestionamiento de los mecanismos de representación en la novelística de Fanny Buitrago. Nueva York, Peter Lang.

Montes Garcés, E. (2007) Relocating Identities in Latin American Cultures. Calgary, University of Calgary Press.

Montes Garcés, E. (e/p) “Con el lápiz en la mano: mujeres y comics a ambos lados del Atlántico", en Revista Canadiense de Estudios Hispánicos.

Mulvey, L. (2009) Visual and other pleasures. Basingstoke, Palgrave Macmillan.

Muñoz, H. (2016) “¿Son arte las series de televisión?” en Index.comunicación: Revista Científica en el Ámbito de la Comunicación Aplicada, 6, (2), pp. 68-82. Disponible en: http://journals. sfu.ca/indexcomunicacion/index.php/indexcomunicacion/article/view/230/202

Oltra, M., y R. Pardo (2015) "Literatura e identidades en el contexto europeo: una aproximación en perspectiva comparada a través de los referentes literarios" en X. Núñez, A. González, C. Pazos y P. Dono (eds.), Horizontes científicos y planificación académica en la Didáctica de Lenguas y Literaturas. Ribeirão, Húmus, pp. 959-974.

One Small Step (2018) Bobby Pontillas y Andrew Chesworth [corto de animación] ChinaEE. UU., Taiko Studios.

Paredes, E. (2010) “La educación mediática como proyecto educativo. Propuesta metodológica para la educación en valores a través del cine de animación infantil” en J. M. Pérez Tornero (coord.), Alfabetización mediática y culturas digitales. Sevilla, Universidad de Sevilla.

Pascual y Cabo, D. (2010) “Construcción social de género en el cancionero infantil español”. Ensayos. Revista de la Facultad de Educación de Albacete, 25, pp. 141-155.

Pereira, C. (2005) Los valores del cine de animación. Propuesta pedagógica para padres y educadores. Barcelona, PPU.

Purl (2019) Kristen Lester [corto de animación]. EE. UU, Pixar.

Rocha, C., y E. Montes Garcés (2010) Violence in Argentine Literature and Film: 1989-2005. Calgary, University of Calgary Press.

Rodríguez Magda. R. M. (2019) La mujer molesta. Feminismos postgénero y transidentidad sexual. Madrid, Ménades.

Sanders, J. (2015) Adaptation and Appropriation. Londres, Routledge.

Saneleuterio, E., y R. López-García-Torres (2018) “Algunos personajes Disney en la formación infantil y juvenil: otro reparto de roles entre sexos es posible" en Cuestiones de género: de la igualdad y la diferencia, 13, pp. 209-224. doi: http://dx.doi.org/10.18002/ cg.v0i13.5390.

Saneleuterio, E., y R. López-García-Torres (2019) “Las películas de animación infantil en la actualidad: El hombre como contraejemplo" en Edetania. Estudios y propuestas socioeducativas, 55, pp. 203-221. Disponible en http://hdl.handle.net/20.500.12466/130

Saneleuterio, E. (2019) "Diseño de un proyecto de investigación sobre la representación de la diversidad en el cine infantil y sus implicaciones educativas" en T. Fernández-Ulloa (ed.), La identidad en el mundo hispano: igualdades y desigualdades en los siglos XIX, XX y XXI a través de diversos textos. Vigo: Editorial Academia del Hispanismo, pp. 233-246.

Soloway, J. (2016) The female gaze [Master class. TIFF Industry Conference]. Disponible en: https:/www.tiff.net/the-review/jill-soloway-conjures-the-goddess/

Žižek, S. (2009) Sobre la violencia: Seis reflexiones marginales. Buenos Aires, Paidós. 